\title{
第 \\ MARCO LEGAL DA PRIMEIRA INFÂNCIA: UM ESTUDO A PARTIR DO CONCEITO DE INTERSETORIALIDADE
}

\author{
LEGAL FRAMEWORK ON EARLY CHILDHOOD: A STUDY BASED ON THE \\ CONCEPT OF INTERSECTORIALITY
}

\section{MARCO JURÍDICO DE LA PRIMERA INFANCIA: UN ESTUDIO BASADO EN EL CONCEPTO DE INTERSECTORIALIDAD}

\author{
Mariana Scaff Haddad Bartos ${ }^{1}$
}

\begin{abstract}
Resumo: O presente artigo tem como referenciallegislativo norteadoro Marco Legal da Primeira Infância, lei que estabelece os princípios e as diretrizes para as políticas públicas para crianças até os seis anos. Busca-se analisar a intersetorialidade proposta pelo Marco Legal da Primeira Infância, a lém de a presentar o processo de construção da lei, até sua sanção - percurso ainda pouco explorado academicamente. Utilizando metodologia qualitativa e estudo de caso como método de pesquisa, espera-se ter uma compreensão mais ampla da utilização da intersetorialidade como conceito e do Marco Legal como principal referencial legislativo do tema da primeira infância. Após percorrer a literatura especializada e a a nálise da lei, é possível considerar que a intersetorialida de proposta pelo Marco Legalda Primeira Infância está coerente com a literatura, além de ser um conceito que possui grande destaque dentro da lei.
\end{abstract}

Palavras-chave: Intersetorialidade; Primeira Infância; Marco Legal da Primeira Infância .

Abstract: This study has the Legal Framework on Early Childhood as guiding legislative reference. The law establishes the principles and guidelines for public policies for children up to six years. Seeks to analyze the intersectoriality proposed by the Legal Framework on Early Childhood, in addition to presenting the process of developing the law, until its sanction - a path that has not yet been explored academically. Using qua lita tive methodology and case study as a research method, it is expected to have a broader understanding of the use of intersectoriality as a concept and the Legal Framework as the main legislative framework for the theme of early childhood. After going through the specialized literature and analyzing the law, it is possible to consider that the intersectorality proposed by the Legal Framework is consistent with the literature, in addition to being a concept that has great prominence within the law.

Keywords: Intersectoriality; Early childhood; Legal Framework on Early Childhood.

Resumen: Este artículo tiene como referencia legislativa el Marco Jurídico de la Primera Infancia. La ley establece los principios y lineamientos para las políticas públicas para niños de hasta seis años. Busca analizar la intersectorialidad propuesta por el Marco Jurídico de la Primera Infancia, además de presentar el proceso de desarrollo de la ley, hasta su sanción, un ca mino que aún no se ha explora do académicamente. Utilizando metodología cualitativa y estudio de caso como método de investigación, se espera tener una comprensión más amplia del uso de la intersectorialidad como concepto y el Marco Jurídico como el principal marco legislativo para el tema de la primera infancia. Después de revisar la literatura especializada y analizar la ley, es posible considerar que la intersectorialidad propuesta por el Marco Jurídico es consistente con la literatura, además de ser un concepto que tiene una gran importancia dentro de la ley.

Palabras clave: Intersectorialidad; Primera infancia; Marco Jurídico de la Primera Infancia.

\footnotetext{
${ }^{1}$ Professora do curso de medicina da Universidade Nove de Julho. Mestre em Administração Pública e Governo pela Fundação Getulio Vargas (FGV). Graduada em Gestão de Políticas Públicas pela Universidade de São Paulo (USP). E-mail: marishb@hotmail.com. ORCID: https://orcid.org/0000-0002-5478-3480.
} 


\section{Introdução}

Tratar de primeira infância é algo bastante gratificante. É um período que remete à esperança, à inocência e ao aprendizado. As crianças não são cidadãs do futuro, como frequentemente são tratadas: são cidadãs do presente e sujeitos de direitos. Assim, a primeira infância é uma etapa da vida que tem sua própria essência e plenitude.

O Marco Legal da Primeira Infância, lei sancionada em 2016, é apontado como um grande avanço no campo da primeira infância e no quadro da legislação sobre o tema no Brasil. Embora aborde diversos temas, é ainda pouco analisado do ponto de vista acadêmico. $\mathrm{O}$ tema da primeira infância traz consigo a importância de um olhar integral e a intersetorialidade como um pressuposto para que as crianças não sejam tratadas como uma fração de pessoa e sim como um todo.

Os estudos que trabalham o conceito de intersetorialidade vêm conquistando cada vez mais espaço, sendo uma discussão desafiadora (BRONZO, 2007). Embora o Marco Legal da Primeira Infância traga o conceito como um de seus principais pilares, é pouco comum que seja analisado em uma ótica intersetorial. Objetiva-se aqui que a intersetorialidade seja trabalhada como principal conceito teórico, a fim de subsidiar as discussões que envolvem o Marco Legal da Primeira Infância.

Deste modo, além de estabelecer um diálogo com a literatura já existente, tem-se uma expectativa de que este estudo possa preencher algumas lacunas. Afora a relação da intersetorialidade com Marco Legal da Primeira Infância, é identificada também a necessidade de estudos que se aprofundem no Marco Legal.

Este artigo está organizado em sete seções, incluindo esta introdução. A segunda seção trabalha o conceito da intersetorialidade e a terceira seção apresenta a metodologia utilizada. A quarta, explica o que é a primeira infância e a importância de políticas públicas para esta faixa etária. A quinta seção é destinada ao Marco Legal da Primeira Infância, na qual é detalhado o processo de construção da lei. Por se tratar de um conteúdo que ainda é pouco presente em trabalhos acadêmicos, a seção pretende contribuir com a discussão ao colocar como a lei foi sendo estruturada ao longo do tempo, além dos atores que estavam presentes e os desafios enfrentados. A sexta seção analisa a intersetorialidade que é proposta pelo Marco Legal da Primeira Infância, de modo a compreender o quanto está dialogando com a literatura e, ao final do artigo, na sétima seção, são apresentadas as considerações finais.

\section{Intersetorialidade}

Os estudos mais recentes que abordam a questão da intersetorialidade e analisam as políticas intersetoriais do país têm demonstrado a importância de tratar os problemas e as soluções em uma perspectiva integrada. Na maior parte da literatura revisada, encontram-se críticas à dinâmica mais setorial das políticas públicas. 
A realidade apresenta seus problemas complexos e mal estruturados e, simultaneamente, as instituições continuam se organizando em setores e as universidades continuam fragmentando o saber em departamentos (MONNERAT E SOUZA, 2011). Observa-se que tanto as políticas econômicas como as políticas sociais constituíram relações e organizações de trabalho com uma estrutura organizacional verticalizada e setorializada, segmentando as áreas de intervenção de modo independente (DUARTE E LEITE, 2006). Todavia, isso não significa que haja um consenso ou uma única orientação dentro de um setor. Pelo contrário, o dia a dia é marcado por conflitos e discussões em torno das ideias e estratégias que integram essa lógica setorial (SANTOS, 2011).

Focando nas políticas sociais, boa parte delas não atua em conjunto e nem dialoga entre si, de modo que não se propõe a desenvolver um esforço institucionalizado e sistemático para que as ações sejam compatibilizadas e para que sejam criadas sinergias e complementaridades, o que resulta numa tônica de verticalização (DUARTE; LEITE, 2006). Políticas que são baseadas em temas como combate à pobreza ou diversidade étnica, por exemplo, não conseguem ficar limitadas às fronteiras de cada setor, até porque se tratam de fronteiras tênues e que se sobrepõem (SANTOS, 2011). Tem-se, deste modo, uma preocupação em integrar problemas e soluções, de forma que a intervenção não ocorra de maneira isolada, principalmente no caso de políticas sociais, com problemas multidimensionais demandando respostas articuladas.

\subsection{Contextualizando o conceito}

O tema da intersetorialidade se fortalece como conceito já na década de 1980, com foco, na época, no setor da saúde (CUNILL-GRAU, 2014). Todavia, Repetto (2009) pontua que é somente em meados da década de 1990 que emerge de fato uma preocupação com a intersetorialidade, quando se detecta como um problema a ausência de sinergia e complementariedade entre os diversos setores responsáveis por políticas públicas.

Para Cunill-Grau (2014), no que se refere às políticas de caráter nacional, é evidente a emergência, principalmente a partir dos anos 2000, de uma tendência na América Latina das novas políticas sociais focadas em direitos, e que adotam a intersetorialidade como um de seus eixos principais. No Brasil, conforme demonstram Cruz e Farah (2016), o movimento sanitarista da década de 1970 já incorpora a intersetorialidade em seu discurso, principalmente no que tange o tema da integralidade no atendimento. De toda forma, é durante o período de redemocratização, descentralização das políticas e fortalecimento dos governos locais que o tema da intersetorialidade se destaca no país. Este contexto de expansão da agenda dos govemos locais e emergência das redes multiníveis aproxima ao debate a questão da intersetorialidade. A governança que emerge indica outro paradigma de gestão, o qual se contrapõe às bases de sustentação do governo tradicional, fragilizando as características que sustentavam os modelos tradicionais de governo (BRONZO, 2007). A relação entre o tema da intersetorialidade e o 
contexto de descentralização pós redemocratização é relevante ao reforçaro caráter horizontal do conceito, de maneira que vai no sentido oposto das relações rígidas e hierárquicas que predominavam até então.

\subsection{Debate na literatura}

Em grande parte da literatura, a complexidade dos problemas e suas diversas dimensões e multicausalidades estão diretamente relacionadas ao tema da intersetorialidade, o qual acaba tendo como perspectiva básica a necessidade de um olhar integral, ou seja, a integralidade (BRONZO, 2007). Duarte e Leite (2006) atribuem o surgimento da intersetorialidade a partir de insatisfações relacionadas à capacidade das organizações sociais em dar respostas aos problemas complexos que vêm com a nova ordem mundial. Segundo Jaccoud (2016, p. 15) é um tema que "vem ganhando destaque como estratégia relevante para gestão pública, em especial diante de problemas caracterizados como complexos e de públicos marcados por vulnerabilidades".

É um conceito, porém, ainda utilizado sem muita clareza tanto por gestores, como por acadêmicos (BRONZO, 2007), sendo comum tratá-lo de maneira ambígua e genérica. Em boa parte da literatura, inclusive aquelas que se tornaram referências no tema, não existe consenso no que se refere à definição e abrangência do conceito. Cruz e Farah (2016) mostram que é possível identificar na literatura um sentido restrito e um sentido ampliado do conceito de intersetorialidade. O sentido restrito define a intersetorialidade como "compartilhamento de ações e a soma de esforços entre diferentes setores e agências de uma mesma esfera de governo" (CRUZ; FARAH, 2016, p. 6), levando em conta apenas as relações internas do setor público. Já o sentido ampliado abarca outros atores que não apenas o Estado, como o setor privado e a sociedade civil.

Nesse sentido ampliado do termo, Teodósio (2008) utiliza a terminologia "Parcerias TriSetoriais" para tratar justamente das interações entre atores do Estado, organizações da sociedade civil e empresas, incluindo a questão do investimento social privado na dimensão da intersetorialidade. No mesmo contexto, Bronzo (2007, p. 01) analisa a perspectiva da intersetorialidade sob a ótica da governança, mostrando que o termo intersetorialidade também pode ser utilizado "para se referir à interação entre os diversos setores - Estado, mercado e sociedade - em uma visão de governo relacional e multinível".

Aparece também certa controvérsia no que diz respeito ao caráter de coordenação que a intersetorialidade pode trazer consigo. Alguns autores relacionam direta ou indiretamente articulação intersetorial com coordenação de ações. Repetto (2009) utiliza o termo "coordinación pro-integralidad", reforçando o caráter complexo de uma coordenação que promove a integralidade e entendendo esta coordenação como uma função estatal, a qual pode ser traduzida em uma articulação intersetorial. Por suavez, Serra (2005), ao tratar a questão da transversalidade, relaciona coordenação horizontal, projeto intersetorial e gestão compartilhada, ressaltando, 
porém, que a intersetorialidade tem algumas particularidades em relação à coordenação. Na mesma linha deste último, Cunill-Grau (2014) reconhece que a coordenação é sempre necessária para assegurar que diversos setores responsáveis por implementar uma política não apresentem inconsistências, porém reforça que, sozinha, a coordenação não se traduz em integração e não pode ser tratada exclusivamente como sinônimo de intersetorialidade. Já Bronzo é mais enfática ao particularizar e diferenciar os conceitos:

\begin{abstract}
(...) a intersetoria lidade se diferencia, ainda que de maneira sutil, da articulação ou coordenação das ações, uma vez que, em uma versão "forte", envolveria alterações nas dinâmicas e nos processos institucionais e no desenho e conteúdos das políticas setoriais. Coordenação é um termo que sinaliza um processo de articulação institucional que não pressupõe, necessariamente, alterações nas estruturas ou dinâmicas existentes nos diversos setores. (2007, p. 15).
\end{abstract}

Um ponto comum na literatura é a ideia de que a realidade é multifacetada, com problemas de diversas dimensões, os quais interagem entre si e se reforçam mutuamente. Sendo assim, tais problemas demandam soluções que envolvam não apenas um setor, mas sim uma estratégia coletiva envolvendo diversos setores, áreas e atores. Segundo Pires (2016), a intersetorialidade surge nos debates de forma até intuitiva quando se constata que os problemas sociais reais, para os quais as políticas públicas são destinadas, são necessariamente multifacetados e não obedecem às divisões setoriais das burocracias públicas.

\title{
2.3 Tipos e intensidades de integração
}

Cunill-Grau (2014) se dedica a explorar a questão da integração como resultado e expressão do trabalho intersetorial. Segundo a autora, a relação entre setores pode se dar de diferentes maneiras e a integração resulta em sua forma mais intensa e complexa, como se fosse uma variável da integralidade. As próprias definições de intersetorialidade, de acordo com CunillGrau (2014), expressam diferentes facetas de integração - colaboração, convergência, consolidação e integração - e algumas questões podem ajudar a nortear este entendimento: o que se integra; quem intervém na integração; onde se dá a integração; como se realiza a integração.

Nesse sentido, Lotta e Favareto (2016) mostram que quando programas ou temas de políticas públicas são organizados horizontalmente, com integração entre eles, a intersetorialidade se concretiza. Os autores apontam que o grau em que se dá essa intersetorialidade varia conforme os temas estão articulados e como se concretizam, ou seja, depende se existe uma efetiva integração ou apenas uma justaposição de políticas. Bronzo (2016) também afirma que a integração entre os setores é, em si, a intersetorialidade e que essa integração é necessária quando se pretende ir além de uma provisão de bens e serviços, como, por exemplo, quando se quer desenvolver capacidades ou alterar comportamentos. 


\title{
2.4 Intersetorialidade e a ideia de rede
}

O conceito de rede também é muito utilizado neste tipo de literatura. Além de conciliar diversos conhecimentos de maneiraintegrada, uma política intersetorial deve contar com a relação de diferentes profissionais além dos burocratas, dos políticos e dos próprios cidadãos. O sistema de rede traz a ideia de vínculo, de conexão, e, principalmente, de relações horizontais (CKAGNAZAROFF; MOTA, 2003). A ideia é que sejam estabelecidas relações entre setores, instituições governamentais e não governamentais com o objetivo de enfrentar problemas sociais complexos que ultrapassem a alçada de um só setor de governo ou área de política pública (MONNERAT; SOUZA, 2011).

Ambrózio (2013) trabalha com a ideia de redes de relacionamento, as quais são informais na circulação e na articulação e muitas vezes influenciadas por temas de interesse e pela atuação anterior dos burocratas. Estas redes, segundo o autor, são possíveis potencializadoras de intersetorialidade. Nesse mesmo sentido, Junqueira mostra que:

\begin{abstract}
As redes sociais - como um conjunto de pessoas e organizações que se relacionam para responder demandas e necessidades da população de maneira integra da, ao mesmo tempo respeitando o sabere a autonomia de ca da membro -, constituem um meio de tornar mais eficaz a gestão das políticas sociais, otimizando a utilização dos recursos disponíveis. Na medida em que preservam a identidade de cada membro e sua competência, com atores públicos, estatais e privados, possibilitam a articulação e a ação intersetorial e a superação da incapacidade da gestão dos microprocessos isolados das políticas sociais (2016, p. 10).
\end{abstract}

Pereira e Teixeira (2013) apontam que intersetorialidade e rede são conceitos ligados um ao outro, de modo a proporem integração e articulação de saberes e serviços em oposição à setorização e à especialização. Em uma lógica de atuação das redes como um suporte, Bronzo (2010, p. 132) mostra que a ideia de rede "pressupõe uma retaguarda de serviços e apoio, capaz de ser mobilizada pelos agentes públicos e combinados diante de cada situação específica". Responder a estas situações ou demandas de maneira adequada e eficaz significa estar sujeito à disponibilidade de serviços, programas e ações governamentais e não governamentais.

Tratando também de redes de governança, Bichir, Oliveira e Canato (2016) mostram que a compreensão de como os arranjos intersetoriais se efetivam está também ligada ao entendimento das diversas redes e padrões de vinculação entre organizações e atores envolvidos nos processos de decisão e de implementação. Assim, o entendimento comum é de que não existe hierarquia ou poder centralizado na rede, uma vez que são exatamente as relações que importam. O objetivo é gerar sinergia, integrando e articulando instituições, pessoas, saberes e experiências (JUNQUEIRA, 2016). 


\subsection{Desafios}

Bronzo (2007) cita inúmeros desafios relacionados ao trabalho intersetorial, mas deixa clara a dificuldade de apresentar soluções para enfrentá-los. Como um desafio mais concreto, a autora cita a articulação do ponto de vista financeiro, a qual demanda forte ade são política e estruturas e práticas institucionais adequadas, considerando o orçamento por rubricas um nó central para o desenvolvimento da intersetorialidade. Assim, tal como mostram Cruz e Farah (2016), a implementação da intersetorialidade exige mudança da cultura organizacional, dos processos estabelecidos e da interaçãoentre os diversos atores envolvidos. Além disso, a demanda por ações integradas entre diferentes áreas rompe com a visão fragmentada e requer que os objetivos, metas e procedimentos de diversos órgãos governamentais sejam integrados, o que implica reformular suas estratégias de ação, formas de destinar recursos públicos, sua estrutura organizacional e burocrática. Tais mudanças ficam ainda mais complexas para os órgãos mais estruturados e consolidados em termos de financiamento e regulamentação (DUARTE; LEITE, 2006).

Problematizar a intersetorialidade impõe desenvolver modelos integrativos de gestão governamental. Os setores envolvidos interagem pouco, o elo entre eles ainda é fraco, com baixa troca de informações, experiências e trabalho em equipe (SANTOS, 2011). Teodósio (2008, p. 8) mostra a complexidade em torno das relações intersetoriais nas interações entre atores da sociedade civil, do Estado e do mercado, trazendo as disputas hegemônicas que as lutas na sociedade civil permitem e as relações permeadas por práticas não lineares e pela ocorrência de processos simultâneos "de conflito e cooperação, engajamento e distanciamento, e resistência e adesão". São diversos os motivos de resistência, associada muitas vezes ao deslocamento de poder, de decisões e/ou do conhecimento; ou até mesmo a mudanças nos processos de trabalho (DUARTE; LEITE, 2006). Mesmo quando a intersetorialidade é consenso e diretriz, contando com a adesão de um conjunto expressivo de atores, é grande a chance de aparecerem problemas em sua implementação:

\footnotetext{
O desafio da intersetoria lida de consiste, portanto, em como unir, em uma ação conjunta, instituições com objetivos, dinâmicas e culturas organizacionais distintas. A resposta, mais ou menos óbvia, está nos objetivos comuns que possam ser identificados, ou nos resultados que se queira produzir conjuntamente. A elaboração de diagnósticos comuns ou pactuados dos problemas pode ser um meio que possibilite a intersetorialida de. A perspectiva da co-responsabilização ga nha relevância, uma vez que as diversas instituições passam a ser responsáveis pelo alcance dos resultados ou objetivos comuns acordados (BRONZO, 2007, p. 17)
}

Ao analisar a implementação de programas de transferência de renda, Bichir (2015) discorre justamente sobre os desafios da coordenação intersetorial. Segundo a autora, a articulação intersetorial de programas e políticas envolve a concepção de capacidades para efetivar a intersetorialidade, as quais dependem fortemente de mecanismos e institucionalidades 
construídos, ou não, ao longo do tempo. Ainda sobre a coordenação intersetorial, Falcão (2016), ao estudar alguns programas do então MDS, justifica a dificuldade de superar o modelo de coordenação e chegar a outro nível de intersetorialidade. $\mathrm{O}$ autor pontua que existe uma complexidade no modelo vigente: para chegar a um formato que ele considera ideal, é necessário rever a divisão de responsabilidades e competências e readequar as equipes das políticas públicas, a legislação e o financiamento. Também nesta lógica de análise de políticas e programas, Bichir et al. (2018, p. 1) discutem os desafios da implementação da São Paulo Carinhosa, política municipal para o desenvolvimento integral da primeira infância na cidade de São Paulo, problematizando "dimensões da implementação que devem ser consideradas no aperfeiçoamento de agendas intersetoriais". Assim, é possível observar que as análises e os estudos de políticas públicas acabam trazendo os desafios encontrados. Por meio da literatura especializada fica claro que diferentes áreas e atores envolvidos no processo têm altos níveis de conflito, disputa política e competição em torno das estruturas de poder (MONNERAT; SOUZA, 2011).

\section{Opções Metodológicas}

Segundo Webster e Watson (2002), a revisão de literatura auxilia no desenho da pesquisa e na verificação de possíveis lacunas envolvendo a temática selecionada. Desse modo, entendese que, principalmente na área da administração pública, existe uma lacuna na literatura tanto em relação a trabalhos que se aprofundem no Marco Legal da Primeira Infância. Ainda menos comuns são aqueles trabalhos que relacionam o Marco Legal com a intersetorialidade. Assim, objetiva-se neste artigo, além de estabelecer um diálogo com a literatura já existente, preencher essa lacuna.

Utilizando metodologia qualitativa e tendo estudo de caso (STAKE, 2000) como método de pesquisa, espera-se ter uma compreensão mais ampla da utilização da intersetorialidade como conceito e do Marco Legal como principal referencial legislativo do tema da primeira infância. A pesquisa qualitativa, segundo Godoy (1995, p. 58), "parte de questões ou focos de interesses amplos, que vãose definindo à medida que o estudo se desenvolve”. Por meio da leitura de Godoy (1995), pode-se afirmar queesta pesquisa tem abordagem qualitativa, de maneira que se concentra na ampla compreensão do que se pretende estudar e na preocupação com todo o processo e não simplesmente com os resultados.

Assim, entende-se que a pesquisa e a análise documental são fundamentais neste estudo. Godoy (1995, p. 21) coloca que a pesquisa documental envolvejustamente o "exame de materiais de natureza diversa, que ainda não receberam um tratamento analítico, ou que podem ser reexaminados, buscando-se interpretações complementares”. Além disso, a intersetorialidade é o principal referencial teórico e principal conceitodeste trabalho. Deste modo, optou-se por realizar uma revisão de literatura que pretende contribuir para a discussão do conceito de intersetorialidade, sem, contudo, ter a pretensão de apresentar uma definição acabada ou única do 
conceito. Além disso, o artigo busca contextualizar e apresentar o debate que existe na literatura acerca da questão intersetorial, a fim de dar subsídios para a análise do Marco Legal da Primeira Infância.

O Marco Legal da Primeira Infância, além de analisado integralmente para que as principais características e avanços da lei fossem destacados, teve também seu processo de construção detalhado. Para isso, foram revisados documentos, pareceres, requerimentos e notícias, além do projeto original e dos documentos que refletem a discussão da proposta no Congresso, comparando-os ao tex to que foi sancionado. As pesquisas se deram, em um primeiro momento, no site da Câmara dos Deputados, que é por onde chegou o então Projeto de Lei da Primeira Infância. No campo de busca do site, foi inserido o número do PL - 6.998/2013. Com os resultados, os quais puderam ser aprimorados com as opções de filtros, foi possível ter acesso às propostas que o projeto foi recebendo, aos discursos e pronunciamentos e às notícias relacionadas ao tema. Em seguida, as pesquisas se concentraram no site do Senado Federal, que foi para onde o PL foi encaminhado no início de 2015. No site do Senado, ao inserir a nova denominação do projeto - PLC 014/2015 - é possível ter acesso a toda a ficha de tramitação, com os despachos, ações legislativas, pareceres, relatórios e documentos relacionados.

\section{Primeira Infância}

\subsection{A construção social do conceito de infância}

As Ciências Sociais e Humanas demoraram para incluir a infância como objeto de pesquisa, de modo a compreender a criança como sujeito histórico e de direitos (Nascimento, Brancher e Oliveira, 2008). O conceito de infância como uma construção social reforça a ideia de que pertencer a um determinado grupo etário significa seguir as normas destes grupos e está ligado a um processode diferenciação entre o mundo das crianças e o mundodos adultos, duas categorias distintas não somente pela idade biológica, como também por investimentos culturais que se materializam no vestuário, nos hábitos e nas atividades cotidianas (Ramos, 2013). Na Idade Média, a primeira infância correspondia à primeira idade, que assim como a segunda idade e a terceira idade - etapas que iam até os 21 anos-, não era valorizada pela sociedade. Foi apenas nos séculos 19 e 20 que ocorreu o entendimento real de infância, de modo que na contemporaneidade esta construção social é concretizada a partir do momento em que se estabelecem valores morais e expectativas de condutas para as crianças (NASCIMENTO; BRANCHER; OLIVEIRA, 2008).

A primeira infância é um período da infância, a primeira etapa: é a fase que compreende do zero aos seis anos de idade. É neste período que o cérebro passa por um intenso amadurecimento e que ocorre o desenvolvimento motor, cognitivo e linguístico e o aprendizado social e afetivo da criança (BARAN; SAUMA; SIQUEIRA, 2014). Assim, a ideia de um desenvolvimento saudável na primeira infância está ligada a estrutura de uma sociedade próspera 
e sustentável. É um período que traz consigo a ambivalência “presente e futuro"(RNPI, 2010), fazendo com que o cuidado na infância de um indivíduo seja determinante para o resto de sua vida. A primeira infância torna-se uma etapa crucial no desenvolvimento do ser humano, momento em que se consolidam os alicerces para as aprendizagens posteriores e, consequentemente, a base de toda uma vida (CAMPOS, 2010).

\subsection{Políticas Públicas para a primeira infância}

A partir das evidências científicas, fica clara a importância de investimentos em políticas públicas que promovam o cuidado integral da criança nos primeiros seis anos de vida. O Estado deve estabelecer as diretrizes e os critérios a fim de orientar todos aqueles que trabalham pela primeira infância, com a ciência de que as carências da infância podem resultar em marcar por toda a vida e que tentar corrigi-las mais tarde, durante a maturidade, é um processo nem sempre bem-sucedido (QUEIROZ, 2016). Reconhecer as crianças como cidadãs é indispensável para que as políticas para a primeira infância, além de efetivadas, sejam permanentes e se mantenham independente de qualquer governo ou partido político (ALMEIDA, 2016).

Ao trazer ao debate às políticas públicas para a primeira infância, percebe-se que o tema da intersetorialidade deve ser um dos principais pilares se o foco é o desenvolvimento integral da criança, de modo que ela seja respeitada e atendida integralmente. Tem-se, assim, a importância da intersetorialidade nas políticas públicas voltadas ao desenvolvimento integral da primeira infância, abordando os problemas a partir de um entendimento da criança como pessoa, cidadã e sujeito de direitos.

\section{Marco Legal da Primeira Infância}

\subsection{Histórico e processo de construção da lei}

A Lei n. 13.257, mais conhecida como Marco Legal da Primeira Infância ou Estatuto da Primeira infância, foi sancionada em 8 de março de 2016 e é considerada uma inovação e um grande avanço no campo da primeira infância. Antes de passar pelo Executivo, o então Projeto de Lei teve uma trajetória que começou cinco anos antes, em 2011, com o lançamento da Frente Parlamentar da Primeira Infância, composta por mais de 200 parlamentares. Essa Frente chegou a organizar, em abril de 2013, um semináriointernacional como tema do MarcoLegal da Primeira Infância e em dezembro do mesmo ano apresentou o Projeto de Lei da Primeira Infância - o PL $6.998 / 2013$.

O texto do PL trazia em seu conteúdo alterações e inclusões no Estatuto da Criança e do Adolescente (ECA), reforçando a necessidade de uma atenção específica nas crianças de até seis anos de idade, e os princípios para a elaboração de políticas públicas para a primeira infância. A relevância do projeto é justificada por meio de tópicos argumentativos, como os direitos das crianças, a questão pedagógica, o retorno em termos econômicos, o trabalho extradomiciliar da 
mulher, a justiça social e as contribuições da neurociência. Além disso, a nomeação 'Marco Legal da Primeira Infância' já aparece no PL, enfatizando o papel do Poder Legislativo neste processo.

Em janeiro de 2014, o PL foi designado, incialmente, às seguintes Comissões: Ciência e Tecnologia, Comunicação e Informática; Seguridade Social e Família; Finanças e Tributação e Constituição e Justiça e de Cidadania. Alguns dias depois, foi incluída também a Comissão de Direitos Humanos e Minorias. Deste modo, devido à distribuição a mais de três comissões, a presidência da Câmara dos Deputados decide criar uma Comissão Especial, de forma que esta possa apreciar a matéria e emitir um parecer em relação ao PL 6.998/2013. Assim, composta por 23 membros titulares e igual número de suplentes, cria-se, por ato da Presidência, a Comissão Especial da Primeira Infância. Para a presidência da Comissão foi eleita a Deputada Cida Borghetti (PROS/PR) e indicado como relator o Deputado João Ananias (PCdoB/CE). Ainda sobre a Comissão, importante frisar o curto espaço de tempo em que se deu su a criação, sua composição e sua instalação, de maneira que todo este processo se deu nos meses de fevereiro e março de 2014.

Observa-se que dentro do prazo estabelecido após a criação da comissão - duas semanas - foram apresentadas dez emendas ao projeto, sendo uma emenda da Deputada Jandira Feghalli (PCdoB/RJ), quatro emendas do Deputado Eduardo Barbosa (PSDB/MG) e cinco emendas do Deputado Marcos Rogério (PDT/RO). A primeira emenda propunha alterar a definição de infância e primeira infância, sendo acatada apenas em relação à primeira infância, visto que a definição de infância foi retirada posteriormente. A segunda emenda, a qual tratava da redução do prazo para elaboração dos planos estaduais e municipais pela Primeira Infância, não foi aprovada. A terceira e a quarta emendas, porsua vez, foram contempladas ao proporem a inclusão das expressões "crianças com deficiência" e "existência de deficiência". A quinta e a sexta emendas dispunham sobre a substituição da expressão "criança pequena" por "criança de zero a seis anos" e da supressão dos termos "promoção e participação", respectivamente. É possível considerá-las aprovadas visto que no Substitutivo, ao tomarem outras formas, as expressões não constavam mais. Já a sétima emenda, trouxe, mesmo que de maneira indireta, a discussão sobre sexo e gênero. Foi proposto que a palavra "gênero" fosse excluída do documento, proposta esta aceita e aprovada com a justificativa de que não é função do presente PL tratar desta polêmica. A oitava, assim como a décima emenda, ficaram prejudicadas visto que ambas propunhammodificar ou retirar expressões que não foram mais contempladas no Substitutivo. Por fim, a nona emenda, aprovada nos termos do Substitutivo, tinha como objetivo acrescentar a expressão "com apelo comercial" em relação à temática da publicidade infantil.

Ao longo de 2014, a Comissão organizou mais um seminário internacional sobre o tema, além de seminários regionais em quatro capitais do país - Porto Alegre, Curitiba, São Paulo e Fortaleza -, e duas audiências públicas. Ao analisar a tramitação do projeto, nota-se que os seminários regionais foram resultados de requerimentos de deputados da Comissão, de modo a 
levar a discussão e discutir o projeto em seu respectivo estado. As audiências públicas, por sua vez, ocorreram ambas em maio de 2014 e contaram com representantes e debatedores do Poder Executivo - em especial na $1^{\text {a }}$ Audiência Pública - e de organizações da sociedade civil com atuação no tema da primeira infância - em especial na 2a Audiência Pública.

Importante reforçar esta representação de fora do Poder Legislativo na construção do Marco Legal. Além da presença nas Audiências Públicas, o Poder Executivo também contribuiu por meio de diversas áreas:

Foram realizadas sucessivas reuniões e contatos com dirigentes e técnicos de setores dos Ministérios da Educação, da Saúde, do Desenvolvimento Social e Combate à Fome, da Secretaria de Direitos Humanos e da Secretaria de Assuntos Estratégicos. Deles provieram valiosas contribuições, seja em forma de reflexões que levaram a ajustes ora de forma, ora de conteúdo, seja como sugestões pontuais de itens que foram modificados ou agregados. (BRASIL, 2016a,p. 16).

Além do Legislativo e do Executivo, outros atores estavam igualmente ativos nesse processo. A sociedade civil, principalmente representada pela Rede Nacional Primeira Infância (RNPI), formada por mais de 200 organizações que atuam direta ou indiretamente no tema da primeira infância, e conselhos como o Conselho Nacional dos Direitos da Criança e do Adolescente (Conanda) tiveram forte influência nas discussões e no conteúdo que foi produzido, além do Ministério Público e de pesquisadores de diversas áreas relacionadas à primeira infância.

Em novembro de 2014, foram abertas cinco sessões para apresentação de emendas ao Substitutivo, tendo sido apresentadas 25 novas emendas dentro do prazo estabelecido, das quais 20 foram aprovadas. Das emendas aprovadas, as quais apresentavam, em sua maioria, sugestões de novas redações, e das alterações feitas pelo relator, já com as sugestões encaminhadas pelo Poder Executivo, destaca-se o tema da licença-paternidade. O Substitutivo estabelecia a licença em trinta dias, a qualé alterada para umperíodo de quinze dias, além dos cinco dias já concedidos.

Ao final de 2014, o PL foi aprovado pela Comissão Especial da Primeira Infância. O parecer do relator reconhece a iniciativa legislativa de colocar a primeira infância no debate e no foco da atenção pública, com mérito inegável e indiscutível, sustentado pelos argumentos da justiça social, da redução das desigualdades a partir da primeira infância, da construção da equidade e dos direitos das crianças. A análise do parecer mostra que foram rejeitados alguns pontos que significariam ainda mais avanços nesta temática. Sobre a publicidade infantil, ao analisar o projeto de lei original, seu Art. $2^{\circ}$ acrescentava ao ECA um trecho que foi objeto de debate durante todo o processo de análise do PL e que desaparece posteriormente: "Fica terminantemente proibida a publicidade voltada ao público infantil nos meios de comunicação, em especial televisão e radiodifusão, nos horários compreendidos entre 8 horas e 18 horas." (BRASIL, 2013, p. 2). O tema da publicidade se mantém, porém é colocado de maneira mais abrangente, sem especificar horários ou meios de comunicação. Ademais, a questão das licenças 
maternidade e paternidade não constavam no projeto original - foram incluídas ao longo das discussões na Câmara -, mas também não se sustentaram integralmente. Para a licença maternidade havia sido solicitada e argumentada uma ampliação para doze meses, item que se manteve como prorrogação por sessenta dias. Já a licença-paternidade, conforme colocado acima, é prorrogada por quinze dias ao invés de trinta.

Além disso, comparando o tex to original com a versão enviada ao Senado e até mesmo com a versão final da lei, a alteração de uma importante definição é percebida: o tex to original define primeira infância como "período da vida que envolve a fase gestacional, o nascimento e os primeiros seis anos completos, sendo basilar na formação da pessoa, na construção da subjetividade e das interações sociais" (BRASIL, 2013, p. 3), enquanto o texto final fica com a seguinte redação: "Paraos efeitos desta Lei, considera-se primeira infância o períodoque abrange os primeiros 6 (seis) anos completos ou 72 (setenta e dois) meses de vida da criança" (BRASIL, 2016b, não paginado). O período da gestaçãoé suprimido na redação final, contrariando boa parte da literatura que o inclui dentro das etapas da primeira infância. Esta decisão foi abordada no parecer da Senadora Fatima Bezerra, relatora do PLC no Senado: “Apesar de não haver consenso científico a respeito da delimitação desse período da vida da criança, o projeto adotou esse entendimento corroborado pelo Fundo das Nações Unidas para a Infância (UNICEF) e pela Rede Nacional Primeira Infância.”(BRASIL, 2016d, p. 3).

A alguns retrocessos no texto do projeto, soma-se o recurso n. 335/2014, de autoria do deputado Guilherme Campos (PSD/SP), que contestava o caráter conclusivo da Comissão Especial da Primeira Infância e solicitava que o PL fosse submetido ao Plenário (BRASIL, 2014). $\mathrm{O}$ argumento é de que a demanda veio de um importante setor econômico, muito provavelmente incomodado com a ampliação da licença-paternidade proposta pelo PL (BARROS, 2015), a qual, conforme colocado acima, já havia sofrido alterações em relação ao texto original. O recurso foi apresentado no dia 22 de dezembro de 2014, quando a Câmara já entrava em recesso e dias antes de vários dos deputados que assinaram o recurso, incluindo seu autor, perderem o mandato por não terem sido reeleitos. No total, 66 deputados assinaram o documento, o que faria com que o Projeto de Lei não seguisse para o Senado e sim retornasse ao plenário da Câmara dos Deputados. Para que a manobra não tivesse êxito, pelo menos $50 \%$ dos deputados que assinaram o recurso, ou seja, 34 deles, deveriam retirar suas assinaturas até 30 de janeiro de 2015. Um esforço coletivo da sociedade civil e dos parlamentares envolvidos com o PL conseguiu que 39 parlamentares assinassem um requerimento de retirada da assinatura, o que fez com que o PL seguisse a tramitação prevista e fosse enviado ao Senado em fevereiro de 2015 (MATTOS, 2015a; 2015b).

No Senado, o projeto seguiu com a denominação PLC 014/2015 e foi distribuído, em um primeiro momento, à Comissão de Assuntos Sociais (CAS), à Comissão de Direitos Humanos e Legislação Participativa (CDH) e à Comissão de Constituição, Justiça e Cidadania (CCJ), conforme demonstra publicação oficial no Diário do Senado Federal - DSF (BRASIL, 2015). Em 
abril de 2015, o Requerimento n. 279 de 2015, assinado pelo então Presidente da Comissão de Educação, Cultura e Esporte, solicitou, com êxito, que o PLC 014/2015 fosse encaminhado também a esta comissão. Ao final do mesmo ano, outro requerimento, n. 1.420 de 2015, também aprovado por votação, conseguiu que o projeto tramitasse em regime de urgência.

Em fevereiro de 2016, o parecer da Relatora (BRASIL, 2016d) aprova o projeto, reforçando seu mérito e sua adequação jurídica. Tanto o texto do parecer, como a fala da Relatora na sessão de aprovação do projeto reforçam o cuidado e a preocupaçãodas emendas terem apenas o caráter de redação. Assim, as emendas incluídas, todas de redação, tiveram o objetivo de substituir às seguintes expressões: "aos meios de comunicação" por "à comunicação mercadológica" (art. $5^{\circ}$ do projeto), "na formação humana" por "no desenvolvimento do ser humano" (art. 12 do projeto), "Atenção Básica" e "Atenção Primária" por "atenção primária" (art. 19 do projeto), "Unidades Básicas de Saúde" por "unidades primárias de saúde" (art. 20 do projeto), "outros recursos tecnológicos relativos" por "outras tecnologias assistivas relativas" e "valoração moral" por "constrangimento" (art. 21 do projeto). O projeto, então, é aprovado por unanimidade no Senado Federal, sendo encaminhado para sanção - sem vetos - da Presidenta da República(BRASIL, 2016c).

\subsection{Características e avanços}

O Marco Legal da Primeira Infância é composto por 43 artigos e tem como base e concordância a Constituição Federal e o ECA. Cinco leis sofrem alterações ao longo do texto: o próprio ECA, do Artigo 18 ao Artigo 36; a Consolidação das Leis do Trabalho (CLT), no Artigo 37; a Lei n. 11.770, de 2008, no Artigo 38; o Código de Processo Penal (CCP), no Artigo 41; e a Lei n. 12.662, de 2012, no Artigo 43. Já em seu primeiro artigo fica claro o principal objetivo do Marco Legal: "Esta Lei estabelece princípios e diretrizes para a formulação e a implementação de políticas públicas para a primeira infância em atenção à especificidade e à relevância dos primeiros anos de vida no desenvolvimento infantil e no desenvolvimento do ser humano" (BRASIL, 2016b, não paginado). Visando, então, orientar as políticas públicas para a primeira infância, a lei supre algumas lacunas do Estatuto da Criança e do Adolescente em relação às particularidades dos primeiros seis anos de vida. Alguns temas como a amamentação, a licençapaternidade e, inclusive, as crianças que têm seus genitores privados de liberdade não foram tratados no texto do ECA e aparecem de forma concreta no Marco Legal.

Os pontos que tratam dos direitos trabalhistas dos pais estão entre os que mais tiveram visibilidade e repercussão. A inclusão de novos incisos na CLT garante ao empregador celetista dois tipos de licença: uma de até dois dias, para acompanhar consultas médicas e demais exames complementares durante o período de gravidez de sua esposa ou companheira; e a outra de um dia por ano para acompanhar filho de até seis anos em consulta médica. Além disso, as alterações na Lei n. 11.770, de 2008, prorrogam a licença-paternidade, tema que, além de ser um dos mais 
sensíveis entre os parlamentares, foi um dos mais divulgados pela imprensa ao tratar o Marco Legal da Primeira Infância.

Outro tema tratado pelo Marco Legal, em seu artigo $4^{\circ}$, é a questão da participação: por meio de uma abordagem participativa, a criança é incluída na definição das ações que lhe digam respeito, em conformidade com suas características etárias e de desenvolvimento (BRASIL, 2016b). No mesmo sentido, o Marco Legal trata a criança como cidadã de hoje, do presente, e não como cidadã do futuro como frequentemente é chamada. Enquanto o ECA fala em "preparo para o exercício da cidadania" (BRASIL, 1990), o Marco Legal já coloca a criança na condição de cidadã (BRASIL, 2016b). Toda criança é cidadã e é sujeita de direitos.

\section{A Intersetorialidade proposta pelo Marco Legal da Primeira Infância}

Neste tópico, pretende-se analisar a intersetorialidade proposta pelo Marco Legal da Primeira Infância à luz da literatura. Um dos pontos mais presentes no texto do Marco Legal é, de fato, a questão da intersetorialidade. $O$ conceito aparece de diversas maneiras, precedido por substantivos como 'estratégia', 'comitê', 'coordenação' e ‘abordagem' (BRASIL, 2016b). A lei deixa claro que a intersetorialidade deve ser um dos temas centrais no trabalho com a primeira infância e em toda ação governamental neste campo, sendo essencial e indispensável para que o Marco Legal se sustente.

O Artigo $6^{\circ}$ do Marco Legal fala em uma Política Nacional Integrada, a qual deve ter abordagem e coordenação intersetorial. A questão da integração aparece diversas vezes ao longo do tex to, no mesmo sentido que a literatura utiliza ao tratar a intersetorialidade: relacionado a um atendimento integrado (BRASIL, 2016b). Conforme visto, Cunill-Grau (2014) analisa a questão da integração como resultado e expressão do trabalho intersetorial, mas Santos (2011) mostra que integrar a lógica setorial é uma estratégia permeada por conflitos. Mesmo com todas as dificuldades relacionadas à integração, a análise do texto do Marco Legal deixa claro que o entendimento, coerente com a literatura, é de que existe uma relação direta entre integração e intersetorialidade.

Outro ponto que aparece com frequência no texto do Marco Legal e que tem muita conexão com o assunto da integração, tratado acima, é a questão da integralidade. $\mathrm{O}$ termo 'integral' aparece 19 vezes no texto do Marco Legal, muitas vezes em referência ao desenvolvimento da criança (BRASIL, 2016b). Conforme foi observado na literatura sobre primeira infância e sobre pontos inerentes para políticas públicas destinadas a essa faixa etária, o próprio desenvolvimento das crianças entre zero e seis anos é um processo integral, de interação entre aspectos físicos, neurológicos, biológicos, cognitivos e socioemocionais, além das influências ambientais (BARAN; SAUMA; SIQUEIRA, 2014). Assim, para que a criança seja enxergada em sua totalidade, respeitada e atendida integralmente, é necessário que os setores dialoguem para trabalhar em conjunto, de modo a alcançar o desenvolvimento integral da primeira 
infância (CUNILL-GRAU, 2014). Com essa clareza, o Marco Legal tem o cuidado de sempre tratar de desenvolvimento e de atendimento integral das crianças na primeira infância. Além disso, é importante diferenciar os termos, já que aparecem, muitas vezes, no mesmo contexto: integração remete à ideia de integrar, de agrupar ou compartilhar (CUNILL-GRAU, 2014), enquanto integralidade está ligada a uma perspectiva multidimensional, sendo necessária para possibilitar uma visão global (BRONZO, 2007). A literatura mostra que o tema da intersetorialidade tem como perspectiva básica a necessidade de um olhar integral (BRONZO, 2007), sendo a integração entre diversos setores uma possível estratégia para que essa integralidade seja alcançada. Cunill-Grau (2014) reforça que a relação entre setores pode se dar de diferentes maneiras e a integração resulta em sua forma mais intensa e complexa, como se fosse uma variável da integralidade.

O Artigo $7^{\circ}$ do Marco Legal discorre sobre a criação de um comitê intersetorial de políticas públicas para a primeira infância nos diferentes entes federativos. A ideia de comitês intersetoriais é colocada pela literatura como uma possível estrutura para garantir a integralidade no desenho e na execução de uma política, e, nesse sentido, Cunill-Grau (2014) pontua que esse tipo de colaboração mostra que existe uma necessidade de estabelecer arranjos comuns de governança, o que significa espaços ou instâncias onde os setores envolvidos em uma ação intersetorial possam, pelo menos, ex pressar seusinteressese resolver suas diferenças ou conflitos. Por sua vez, Bichir, Oliveira e Canato (2016), ao analisar instrumentos e relações que permitem que a intersetorialidade seja, de fato, efetivada, mostram a importância de estruturas institucionais, como é o caso dos comitês, mas também reforçam que relações informais no cotidiano são também essenciais para a construção de agendas conjuntas. Assim, a iniciativa de comitês intersetoriais, conforme consta no Artigo $7^{\circ}$ (BRASIL, 2016b), reflete a preocupação em estabelecer arranjos entre os setores, porém, conforme também apresentam Bichir, Oliveira e Canato (2016, p. 96): “é importante analisar o que está sendo efetivamente compartilhado entre os vários setores, e se objetivos comuns de atuação estão, de fato, sendo construídos, para além de relações de protocolo".

Logo em seguida, o parágrafo único do Artigo $8^{\circ}$ foca em uma abordagem multi e intersetorial no atendimento dos direitos da criança na primeira infância. Sobre a multissetorialidade, não foi um termo que apareceu com frequência na literatura, salvo CunillGrau (2014), que coloca que, em ação de baixa integração não existem arranjos para a ação intersetorial, salvo algum tipo de instância técnica multissetorial. Cunill-Grau (2005), ao analisar estratégias de promoção à saúde na Argentina, trata a multissetorialidade como a integração de diferentes setores e atores no processo de diagnóstico, planejamento, execução e tomada de decisões. Além disso, mesmo reconhecendo que alguns autores diferenciam ação intersetorial de ação multissetorial, Cunill-Grau (2005) utiliza ambos os conceitos indistintamente.

Mais adiante, o Artigo 10 coloca a estratégia da intersetorialidade como um dos temas a 
serem contemplados na qualificação dos profissionais que atuam nos diferentes ambientes de execução das políticas e programas destinados à criança na primeira infância (BRASIL, 2016b). Nesse contexto, ao tratar a construção federal de intersetorialidade no Programa Bolsa Família, Ambrózio afirma:

\begin{abstract}
a capacidade de liderança do corpo político é decisiva para a entrada da temática da intersetoria lida de na a genda e a priorização por parte dos ministros também é essencial. Porém, tão ou a té ma is importante que o engaja mento do corpo político será o engaja mento das burocracias e a formação de coesão entre elas (2013, p. 344).
\end{abstract}

As modificações no ECA trazidas pelo Artigo 30 do Marco Legal, vão na mesma linha ao acrescentar a questão da formação profissional de modo que favoreça a intersetorialidade. Importante retomar que entre as diferentes facetas de integração que a intersetorialidade pode expressar - colaboração, convergência, consolidação e integração -, 'padrões de qualificação do pessoal' se insere no nível de colaboração (CUNILL-GRAU, 2014).

Ainda em relação às alterações no ECA, a intersetorialidade aparece no Artigo 24 ao tratar a maneira como o Sistema Único de Saúde deve promover a atenção à saúde bucal. Bönecker et al. (2016, p. 281) reforçam esse ponto ao trazer a promoção da saúde bucal comoparte importante da integralidade do cuidado na primeira infância e ao ressaltar que "diferentemente de outros sistemas de saúde públicos decobertura universal, no Brasil optou-se pelainserção da saúdebucal no Sistema Único de Saúde". Segundo os autores, saúde bucal é parte da saúde integral e seus problemas não devem ser vistos como algo fragmentado, já que podem, por exemplo, alterar o desenvolvimento das relações interpessoais e a autoestima da criança.

A questão da intersetorialidade ainda aparece em outros trechos da lei, mesmo que não de maneira literal, mas com possíveis interpretações, como é o caso do "regime de colaboração entre a União, os Estados, o Distrito Federal e os Municípios" no Artigo $8^{\circ}$ (BRASIL, 2016b, não paginado). Segundo Cunill-Grau (2014), a colaboração é uma das possíveis integrações que a intersetorialidade pode expressar. A autora alerta, porém, que as estratégias de colaboração devem estar alinhadas aos propósitos específicos que se objetiva chegar.

Ainda no sentido de trazer referências à intersetorialidade, o Artigo $9^{\circ} \mathrm{e}$ o Artigo 14 dão ênfase ao tema da articulação, colocando, respectivamente, que as políticas para a primeira infância serão articuladas com as instituições de formação profissional, e que as políticas e programas governamentais de apoio às famílias buscarão a articulação de diversas áreas objetivando o desenvolvimento integral da criança (BRASIL, 2016b). A questão da articulação aparece com bastante frequência na literatura, muito relacionada ao grau da intersetorialidade. Conforme trazido anteriormente, Lotta e Favareto (2016) apontam que o grau em que a intersetorialidade se dá varia conforme os temas estão articulados e como se concretizam. Além disso, Pires (2016, p. 67) aponta que é comum a literatura especializada "compreender a 
intersetorialidade como a articulação de conhecimentos e experiências dos diversos atores governamentais no planejamento, execução e avaliação de ações". Por outro lado, importante retomar Bronzo (2007), que se distancia ligeiramentedessarelação, considerando que uma versão mais forte de intersetorialidade pressupõe alterações nas estruturas ou dinâmicas dos setores, $o$ que não necessariamente é encontrado com a articulação institucional.

O Artigo 23 do Marco Legal incluiu mais um parágrafo, o parágrafo $2^{\circ}$, ao Artigo 13 do ECA. Esse novo parágrafo traz a intervenção em rede no atendimento das crianças na primeira infância com suspeita ou confirmação de violência, seja esta de qualquer natureza. Como observado na literatura, intersetorialidade e rede são conceitos ligados um ao outro, e que propõem a integração e a articulação de saberes e serviços (PEREIRA E TEIXEIRA, 2013), que é exatamente o que sugere esse parágrafo da lei ao citar os diferentes serviços que podem dar prioridade ao atendimento das crianças. Essas relações devem ser ainda mais fortalecidas ao lidar com problemas complexos que ultrapassem a alçada de um só setor (MONNERAT; SOUZA, 2011), comoé o caso da violência contra a criança.

Importante notar que a intersetorialidade que está presente no Marco Legal da Primeira Infância se apresenta no sentido mais restrito do conceito. Conforme observado, a intersetorialidade em uma perspectiva restrita não contempla atores do setor privado e da sociedade civil. Essa visão coincide com a intersetorialidade apresentada no Marco Legal, na qual predominam as relações internas do setor público. Embora a lei traga o setor privado em alguns trechos, como ao tratar do Programa Empresa Cidadã - Artigo 38 -, por exemplo, e embora também aponte a importância de participação da sociedade - Artigo $4^{\circ}$, inciso VI; Artigo 11, parágrafo $2^{\circ}$; Artigo 12 -, o texto não traz outros atores além do Estado ao tratar das relações intersetoriais (BRASIL, 2016b). Além disso, tais relações se concentram na mesma esfera de governo, concordando com o que traz Cruz e Farah (2016) ao mostrarem que o sentido restrito do conceito de intersetorialidade está relacionado a uma cooperação horizontal intragovernamental e não intergovernamental, o que seria, de acordo com as autoras, relações entre níveis de governo distintos. Mesmo o texto da lei trazendo a questão da colaboração entre a União, os Estados, o Distrito Federal e os Municípios, a ênfase que a intersetorialidade tem ao longo do Marco Legal se dá nos respectivos âmbitos governamentais.

Ao analisar o protagonismo que a temática da intersetorialidade tem no Marco Legal da Primeira Infância, é fundamental que o conceito seja, de fato, levado em consideração, mesmo com todos os desafios que isso implica. Como aponta Falcão (2016), o Marco Legal da Primeira Infância traz a necessidade de compreender os desafios da intersetorialidade, lembrando que é na implementação que surgem as maiores barreiras ao sucesso. Ainda segundo o autor, as responsabilidades de execução recaem fortemente nos municípios, considerando a estrutura federativa do país, e, dessa maneira, os conceitos previstos no Marco Legal precisam chegar à ponta, respeitandoas especificidades de cada local, as lógicas de atuação e as reais possibilidades. 
Com a ciência de que existem e existirão muitos desafios, torna-se significativo discutir a intersetorialidade presente no Marco Legal da Primeira Infância, seja como conceito literalmente -, seja indiretamente, como a questão do trabalho em rede e da articulação. Por fim, conclui-se que a intersetorialidade que está presente no Marco Legal da Primeira Infância traz consigo a questão da integração e da integralidade, trabalhando corretamente com ambos os conceitos e mantendo coerência com a literatura, assim como ocorre ao tratar de articulação, de colaboração e de intervenção em rede. Mesmo não sendo simples e óbvio encaixar essa intersetorialidade que está na lei dentro de uma definição, é possível afirmar que o sentido restrito do termo predomina ao longo do Marco Legal.

\section{Conclusão}

Este artigo destacou o Marco Legal da Primeira Infância, uma grande conquista em termos legislativos no que se refere ao tema e aos cuidados das crianças de até seis anos. Provavelmente por ser ainda uma lei muito recente, não foi possível encontrar todo o processo de construção do Marco legal em documentos oficiais e trabalhos acadêmicos. Assim, este trabalho pretendeu contribuir para preencher essa lacuna: por meio da revisão documental, buscou-se trazer como se deu a construção da lei, quais foram os atores envolvidos nesse percurso, o protagonismo de cada um e os desafios e problemas que estavam colocados. Ao comparar o projeto original ao tex to que foi sancionado, e analisando os documentos que refletema discussão da proposta no Congresso, fica evidente a influência de diferentes grupos e interesses, inclusive ao tratar de primeira infância que, em um primeiro momento, não parece ser um tema que cause qualquer tipo de polêmica. Alguns itens que poderiam significar ainda mais avanços na temática da primeira infância não se sustentaramintegralmente aolongo das discussões.Éo caso da licença maternidade e da proibição da publicidade infantil. A licença-paternidade pode ser considerada, por meio da análise dos documentos, um dos temas mais sensíveis do Marco Legal ao longo de sua tramitação, tendo sido proposta por mais trinta dias, mas aprovada por mais quinze dias.

No mais, o estudo dos documentos que envolveram a sanção do Marco Legal mostra também manobras que poderiam ter atrasado a aprovação interna do então projeto, baseadas no interesse de setores econômicos. O esforço coletivo para derrubar essas manobras, incluindo atores diversos, como grupos da sociedade civil. Também pôde ser observado por meio dos requerimentos e das notícias vinculadas pelo terceiro setor. As análises dos documentos também possibilitaram ter conhecimento das comissões pelas quais o projeto passou e das emendas que nele foram incluídas. Desse modo, mesmo o Marco Legal representando um grande avanço na temática da primeira infância, os bastidores de sua tramitação mostram que existiram barreiras ao longo de todo o processo de construção da lei, além de alguns recuos, os quais fizeram com que alguns pontos não se sustentassem até o final.

Importante ponderar que esta análise poderia ser complementada por meio de entrevistas 
com diversos atores que estavam presentes desde a elaboração do projeto até a tramitação da lei e sua sanção. Com este tipo de abordagem, questões como a supressão da gravidez do conceito de primeira infância, por exemplo, poderiam ser esclarecidas. São questões que podem constituir uma agenda de pesquisa futura.

Além disso, a lei traz a intersetorialidade como um tema fundamental no trabalho com a primeira infância e em toda ação governamental nesse campo, justificando a necessidade de analisar o conceito. A intersetorialidade é colocada quase como uma necessidade, essencial e indispensável para que o Marco Legal se sustente. A conclusão da análise é de que a lei trabalha corretamente o conceito e mantém coerência com a literatura. Notável, entretanto, recordar o estudo dos documentos da Câmara e do Senado e a comparação do projeto de lei original ao texto final da lei, os quais mostram como o conceito, que sequer era citado incialmente, tornou-se um dos principais pilares do Marco Legal, ganhando protagonismo ao longo do processo de construção da lei.

\section{Referências}

ALMEIDA, O. A. O Marco Legal da Primeira Infância: quais infâncias, quais crianças. In: BRASIL. (2016). Câmara dos Deputados. Centro de Estudos e Debates Estratégicos (Cedes). Primeira Infância: Avanços do Marco Legal da Primeira Infância. Brasília: Cedes, 2016, p. 133141. Disponível em: http://www2.camara.leg.br/acamara/estruturaadm/altosestudos/pdf/obraavancos-do-marco-legal-da-primeira-infancia.

Acesso em: $16 \mathrm{fev} .2020$.

AMBRÓZIO, L. A. Mecanismos da construção federal da intersetorialidade no Programa Bolsa Família: o papel das burocracias. Revista do Serviço Público, Brasília, v. 64, n. 3, p. 327-350, 2013. Disponível em: https://doi.org/10.21874/rsp.v64i3.127. Acesso em: 11 mar. 2020.

BARAN, M.; SAUMA, J.; SIQUEIRA, P. Lembrar, Espelhar e Experimentar: Distanciamentos e sobreposições entre público e especialistas brasileiros sobre o Desenvolvimento na Primeira Infância. Washington, DC: FrameWorks Institute, n.p. 2014. Disponível em: http://www.frameworksinstitute.org/pubs/mtg/earlychildhoodbrazil/index.html. Acesso em: 02 mai. 2020.

BARROS, D. Deputados tentam atrasar projeto de lei da Primeira Infância. Exame, [s.l.], 26 jan. 2015. Disponível em: https://exame.abril.com.br/brasil/deputados-tentam-atrasar-projeto-de-leida-primeira-infancia/. Acesso em 16 jul. 2020.

BICHIR, R. et al. A primeira infância na cidade de São Paulo: o caso da implementação da São Paulo Carinhosa no Glicério. Cadernos Gestão Pública e Cidadania, [s.l.], v. 24, n. 77, dez. 2018. ISSN 2236-5710. Disponível em: http://bibliotecadigital.fgv.br/ojs/index.php/cgpc/article/view/72695/74683. Acesso em: 22 fev. 2020.

BICHIR, R.; OLIVEIRA, M. R.; CANATO, P. Para além da transferência de renda? Limites e possibilidades na articulação intersetorial de políticas sociais. In: MACEDO, J. M.; XEREZ, F. H. S.; LOFRANO, R. (org.). Intersetorialidade nas políticas sociais: perspectivas a partir do programa bolsafamília. Brasília: Cadernos de Estudos Desenvolvimento Social em Debate, n. 26, 2016, p. 81-102.

BRASIL. Lei n. ${ }^{\circ}$ 8.069, de 13 de julho de 1990. Dispõe sobre o Estatuto da Criança e do Adolescente e dá outras providências. Brasília, DF, 1990. Disponível em: 
http://www.planalto.gov.br/ccivil_03/LEIS/L8069.htm. Acesso em: 22 jul. 2020.

BRASIL. Câmara dos Deputados. Projeto de Lei n. 6998/2013. 2013. Altera o art. $1^{\circ} \mathrm{e}$ insere dispositivos sobre a Primeira Infância na Lei n. ${ }^{\circ} 8.069$, de 13 de julho de 1990, que dispõe sobre o Estatuto da Criança e do Adolescente e dá outras providências. Disponível em: https://www.camara.leg.br/proposicoesWeb/prop_mostrarintegra;jsessionid=7FD9A0A27E0026 664BC5E0483C821726. proposicoesWebExterno2? codteor $=1214724 \&$ filename $=$ Tramitacao PL+6998/2013. Acesso em: 16 jul. 2020.

BRASIL. Câmara dos Deputados. Recurso n. 335/2014, de 2014 (Do Sr. Guilherme Campos e Outros).

Disponível

em: https://www.camara.leg.br/proposicoesWeb/prop_mostrarintegra?codteor=1295497\&filename= Tramitacao-PL+6998/2013. Acesso em: 16 jul. 2020.

BRASIL. Senado Federal. Projeto de Lei da Câmara n. ${ }^{\circ} 14$, de 2015 (n. ${ }^{\circ}$ 6.998/2013, na Casa de origem). Dispõe sobre as políticas públicas para a primeira infância e altera a Lei no 8.069, de 13 de julho de 1990, que dispõe sobre o Estatuto da Criança e do Adolescente, o Decreto-Lei no 3.689, de 3 de outubro de 1941 - Código de Processo Penal, a Consolidação das Leis do Trabalho - CLT, aprovada pelo Decreto-Lei no 5.452, de 1o de maio de 1943, a Lei no 11.770, de 9 de setembro de 2008, e a Lei no 12.662, de 5 de junho de 2012. Diário do Senado Federal. Brasîlia, v. 34, p. 64-121, 20 mar. 2015. Disponível em: $\mathrm{http}: / /$ legis.senado.leg.br/diarios/BuscaDiario?tipDiario=1\&datDiario=21/03/2015\&paginaDiret $\mathrm{a}=00064$. Acesso em: 16 jul. 2020.

BRASIL. (2016a). Câmara dos Deputados. Centro de Estudos e Debates Estratégicos (Cedes). Primeira Infância: Avanços do Marco Legal da Primeira Infância. Brasília: Cedes, 2016. (Cadernos de Trabalhos e Debates). Disponível em: http://www2.camara.leg.br/acamara/estruturaadm/altosestudos/pdf/obra-avancos-do-marco-legal-da-primeira-infancia.

Acesso em: 16 jul. 2020.

BRASIL. (2016b). Lei n. ${ }^{\mathbf{1}}$ 13.257, de 8 de março de 2016. Dispõe sobre as políticas públicas para a primeira infância e altera a Lei no 8.069, de 13 de julho de 1990 (Estatuto da Criança e do Adolescente), o Decreto-Lei no 3.689, de 3 de outubro de 1941 (Código de Processo Penal), a Consolidação das Leis do Trabalho (CLT), aprovada pelo Decreto-Lei no 5.452, de 1 o de maio de 1943, a Lei no 11.770, de 9 de setembro de 2008, e a Lei no 12.662, de 5 de junho de 2012. Disponível em: http://www.planalto.gov.br/ccivil_03/_Ato2015-2018/2016/Lei/L13257.htm. Acesso em: $16 \mathrm{fev} .2020$.

BRASIL. (2016c). Senado Federal. Mensagem n. 71 de 2016, da Excelentíssima Senhora Presidente da República. Diário do Senado Federal. Brasília, v. 24, p. 96, 09 mar. 2016. Disponível em: http://legis.senado.leg.br/diarios/BuscaDiario?tipDiario=1\&datDiario=10/03/2016\&paginaDiret $\mathrm{a}=00096$. Acesso em: 16 jul. 2020.

BRASIL. (2016d). Senado Federal. Parecer n. ${ }^{\circ} 02$, de 2016 do Gabinete da Senadora Fátima Bezerra. De Plenário, sobre o Projeto de Lei da Câmara dos Deputados no 14, de 2015 (Projeto de Lei no 6.698, de 2013, na Casa de origem), do Deputado Osmar Terra e outros, que dispõe sobre as políticas públicas para a primeira infância (...). Diário do Senado Federal. Brasília, v. 2, p. 220-241, 03 fev. 2016. Disponível em: https://legis.senado.leg.br/sdleggetter/documento?dm=4318126\&ts=1548950717907\&disposition=inline. Acesso em: 16 jul. 2020 .

BRONZO, C. (2007). Intersetorialidade como princípio e prática nas políticas públicas: reflexões a partir do tema do enfrentamento da pobreza. In:CONCURSODEL CLAD SOBRE REFORMA DEL ESTADO Y MODERNIZACIÓN DE LA ADMINISTRACIÓN PÚBLICA, 10, 2007, Caracas. Anales [...]. Tema: ¿Cómo enfrentar los desafíos de la transversalidad y de la intersectorialidad en la gestión pública?. Documentos de Debate. Serie n. 12. Caracas: Centro Latinoamericano de Administración para el Desarollo, 2007. Disponível em: https://cladista.clad.org/handle/123456789/4504. Acesso em: 11 mar. 2020. 
BRONZO, C. (2010). Intersetorialidade, autonomia e território em programas municipais de enfrentamento da pobreza: experiências de Belo Horizonte e São Paulo. Planejamento e Políticas Públicas, [s.l.], n. 35, p. 119-160, jul./dez. 2010. Disponível em: http://www.ipea.gov.br/ppp/index.php/PPP/article/viewFile/200/194. Acesso em: 09 abr. 2020.

CAMPOS, A. L. Primeira Infância: Um olhar desde a Neuroeducação. Tradução: Eleonor Campos Beuttemmüller. Washington, D.C.: Organização dos Estados Americanos - OEA, 2010. Disponível em: http://iin.oea.org/pdf-iin/RH/primera-infancia-por.pdf. Acesso em 09 set. 2020.

CENTER ON THE DEVELOPING CHILD AT HARVARD UNIVERSITY. A Science-Based Framework for Early Childhood Policy: Using Evidence to Improve Outcomes in Learning, Behavior, and Health for Vulnerable Children. [S.l.], 2007. Disponível em: http://developingchild.harvard.edu/wp-content/uploads/2015/05/Policy_Framework.pdf. Acesso em 09 abr. 2020.

CKAGNAZAROFF, I. B.; MOTA, N. R. Considerações sobre a relação entre descentralização e intersetorialidade como estratégias de modernização de prefeituramunicipais. Revista Economia e Gestão, Belo Horizonte, série E \& G, v.3, n.6, p. 23-41 dez. 2003. Disponível em: http://periodicos.pucminas.br/index.php/economiaegestao/article/view/94. Acesso em: 11 mar. 2020.

CRUZ, M; FARAH, M. Intersetorialidade na atenção à primeira infância em políticas de enfrentamento da pobreza: do Comunidade Solidária ao Brasil Carinhoso. In: JUNQUEIRA, L. A. P.; CORÁ, M. A. J. (org.). Redes sociais e intersetorialidade. São Paulo: Tiki books, 1 ed., v.1, 2016, p. 235-263.

CUNILL-GRAU, N. (2005). La intersectorialidad en el gobierno y gestión de la política social. In: CONGRESO INTERNACIONAL DEL CLAD SOBRE LA REFORMA DEL ESTADO Y DE LA ADMINISTRACIÓN PÚBLICA, 10, Santiago, Chile, oct. 2005. Anales [...]. [S.l.: s.n.], 2005. Disponível em: http://cdim.esap.edu.co/BancoMedios/Documentos\%20PDF/la\%20intersectorialidad\%20en\%20 el\%20gobierno\%20y\%20gesti\%C3\%B3n\%20de\%201a\%20pol\%C3\%ADtica\%20social.pdf. Acesso em: 22 fev. 2020.

CUNILL-GRAU, N. (2014). La intersectorialidad en las nuevas políticas sociales:un acercamiento analítico- conceptual. Gestión y Política Pública, Distrito Federal, México, v. 23, n. 1, p. 5-46, enero/jun. 2014. Disponível em: https://www.redalyc.org/articulo.oa?id=13331169001. Acesso em: 11 mar. 2020.

DUARTE, V. C.; LEITE, M. R. T. A Dif ícil Articulação entre Políticas Setoriais e Intersetoriais - o Componente Educação no Programa BH-Cidadania. In: ENCONTRO DE ADMINISTRAÇÃO PÚBLICA E GOVERNANÇA, São Paulo, nov. 2006. Anais [...]. [S.l.:s.n.], 2005 Disponível em: http://www.anpad.org.br/admin/pdf/ENAPG157.pdf. Acesso em: 09 abr. 2020.

FALCÃO, T. O desafio da intersetorialidade: contribuições a partir do Ministério do Desenvolvimento Social e Combate à Fome. In: BRASIL. (2016a). Câmara dos Deputados. Centro de Estudos e Debates Estratégicos (Cedes). Primeira Infância: Avanços do Marco Legal da Primeira Infância. Brasília: Cedes, 2016, p. 238-243. Disponível em: http://www2.camara.leg.br/a-camara/estruturaadm/altosestudos/pdf/obraavancos-do-marcolegal-da-primeira-infancia. Acesso em: 16 fev. 2020.

GODOY, A. S. Pesquisa qualitativa: tipos fundamentais. Revista de Administração de Empresas São Paulo, v. 35, n. 3, p. 20-29, mai./jun. 1995. Disponível em: http://dx.doi.org/10.1590/S0034-75901995000300004. Acesso em: 09 abr. 2020.

GUARÁ, I.M.F.R. (coord.). Redes de proteção social. São Paulo: Associação Fazendo História: NECA - Associação dos Pesquisadores de Núcleos de Estudos e Pesquisas sobre a Criança e o Adolescente, 2010. (Coleção Abrigos em Movimento, v. 4).

JACCOUD, L. Pobreza, direitos e intersetorialidade na evolução recente da proteção social 
brasileira. In: MACEDO, J. M.; XEREZ, F. H. S.; LOFRANO, R. (org.). Intersetorialidade nas políticas sociais: perspectivas a partir do programa bolsa família. Brasília, Cadernos de Estudos Desenvolvimento Social em Debate, n. 26, 2016, p. 15-34.

JUNQUEIRA, L. A. P. Apresentação. In: JUNQUEIRA, L. A. P.; CORÁ, M. A. J. (org.). Redes sociais e intersetorialidade. São Paulo: Tiki books, 1 ed., v.1, 2016, p. 7-12.

LOTTA, G. S.; FAVARETTO, A. Desafios da integração nos novos arranjos institucionais de políticas públicas no Brasil. Revista de Sociologia e Política, v. 24, n. 57, p. 49-65, mar. 2016. Disponível em: http://dx.doi.org/10.1590/1678-987316245704. Acesso em: 22 fev. 2020.

MATTOS, R. M. (2015a). Marco Legal da Primeira Infância: limite para retirada das assinaturasé sexta-feira. [S.1.]: Rede Nacional Primeira Infância-RNPI, 27 jan. 2015. Disponível em: http://primeirainfancia.org.br/marco-legal-da-primeira-infancia-limite-para-retirada-dasassinaturas-e-sexta-feira/. Acesso em: 16 jul. 2020.

MATTOS, R. M. (2015b). Marco Legal da Primeira Infância consegue assinaturas para ser enviado ao Senado. [S.l.]: Rede Nacional Primeira Infância - RNPI, 30 jan. 2015. Disponível em: http://primeirainfancia.org.br/marco-legal-da-primeira-infancia-consegue-assinaturas-paraser-enviado-ao-senado/. Acesso em 16 jul. 2020.

MONNERAT, G. L.; SOUZA, R. G. Da seguridade social à intersetorialidade: reflex ões sobre a integração das políticas sociais no Brasil. Revista Katálysis, Florianópolis, v. 14, n. 1, p. 41-49, jan./jun. 2011. Disponível em: http://dx.doi.org/10.1590/S1414-49802011000100005. Acesso em: 11 mar. 2020.

NASCIMENTO, C.; BRANCHER, V.; OLIVEIRA, V. A Construção Social do Conceito de Infância: algumas interlocuções históricas e sociológicas. Revista Contexto \& Educação, v. 23, n. 79, p. 47-63, 2008. Disponível em: https://www.revistas.unijui.edu.br/index.php/contextoeducacao/article/view/1051. Acesso em: 09 set. 2020.

NAUDEAU, S. et al. Como investir na primeira infância: um guia para a discussãode políticas e a preparação de projetos de desenvolvimento da primeira infância. Tradução: Paola Morsello. Washington, DC: The World Bank, 2010; São Paulo: Singular, 2011. Disponível em: https://www.mds.gov.br/webarquivos/publicacao/crianca_feliz/Como_Investir_na_Primeira_Inf ancia.pdf. Acesso em: 14 mar. 2020.

PEREIRA, K. Y. L.; TEIXEIRA, S. M. Redes e intersetorialidade nas políticas sociais: reflexões sobre sua concepção na política de assistência social. Textos \& Contextos, Porto Alegre, v. 12, n. $1, \quad$ p. 114-127, jan./jun. 2013. Disponível em: http://revistaseletronicas.pucrs.br/fass/ojs/index.php/fass/article/view/12990. Acesso em: 22 fev. 2020.

PIRES, R. R. C. Intersetorialidade, Arranjos Institucionais e Instrumentos da Ação Pública. In: MACEDO, J. M. XEREZ, F. H. S., LOFRANO, R. (org.). Cadernos de Estudos: Desenvolvimento Social em Debate. Intersetorialidade nas Políticas Sociais: Perspectivas a partir do Programa BolsaFamília. Brasília, DF: Ministério do Desenvolvimento Social e Combate à Fome; Secretaria de Avaliação e Gestão da Informação, n. 26, 2016, p. 67-80. Disponível em: http://aplicacoes.mds.gov.br/sagirmps/ferramentas/docs/Caderno\%20de\%20Estudos\%2026.pdf. Acesso em: 22 fev. 2020.

QUEIROZ, E. C. Marco Legal pela Primeira Infância: uma grande oportunidade. In: BRASIL. (2016). Câmara dos Deputados. Centro de Estudos e Debates Estratégicos (Cedes). Primeira Infância: Avanços do Marco Legal da Primeira Infância. Brasília: Cedes, 2016, p. 82-85. Disponível em: http://www2.camara.leg.br/acamara/estruturaadm/altosestudos/pdf/obraavancos-do-marco-legal-da-primeira-infancia.

Acesso em: 16 jul. 2020.

RAMOS, A. C. A construção social da infância: idade, gênero e identidade infantis. Revista Feminismos, v. 1, n. 3, 2013. Disponível em: 
https://portalseer.ufba.br/index.php/feminismos/article/view/29993/17735. Acesso em: 09 set. 2020.

REPETTO, F. Coordinación y gestión pública integral en América Latina: notas conceptuales. In: Reflexões para IberoAmérica: Planejamento Estratégico. Brasília: ENAP, 2009, p. 11-20.

RNPI. (2010). Plano Nacional pela Primeira Infância: versão resumida. Brasília, 2010. Disponível em: http://primeirainfancia.org.br/wp-content/uploads/2015/01/PNPI-Resumido.pdf. Acesso em: 09 set. 2020.

SANTOS, N. N. A intersetorialidade como modelo de gestão das políticas de combate à pobreza no Brasil: o caso do Programa Bolsa Família no município de Guarulhos. Dissertação (Mestrado em Administração Pública e Governo) - Fundação Getúlio Vargas, São Paulo, 2011. Disponível em: http://bibliotecadigital.fgv.br/dspace/handle/10438/8225. Acesso em: $22 \mathrm{fev}$. 2020.

SERRA, A. La gestión transversal: expectativas y resultados. Revista del CLAD Reforma y Democracia, Caracas, n. 32, jun. 2005. Disponível em: https://www.redalyc.org/articulo.oa?id=357533664002. Acesso em: 22 fev. 2020.

STAKE, R. E. Qualitative case studies. In: DENZIN, N. K.; LINCOLN, Y. S. (ed.) Handbook of Qualitative Research. 2 ed. London: Sage Publications, 2000. cap. 17, p. 443-454.

TEODÓSIO, A. S. S. Parcerias tri-setoriais na esfera pública: perspectivas, impasses e armadilhas para a modernização da gestão social no Brasil. 2008. 266 f. Tese (Doutorado em Administração de Empresas). FGV EAESP, São Paulo, 2008. Disponível em: http://bibliotecadigital.fgv.br/dspace/handle/10438/2537. Acesso em: 11 mar. 2020.

WEBSTER, J; WATSON, R. T. Analyzing the past to prepare for the future: writing a literature review. MIS Quarterly, v. 26, n. 2, p. 13-23, June 2002.

Artigo recebido em: 2020-08-06

Artigo reapresentado em: 2020-09-30

Artigo aceito em: 2020-10-06 